\title{
Relationship between Uricemia and Other Biochemical Markers with the Materno-Fetal Complications during Pre-Eclampsia
}

\author{
B. D. Tshibuela ${ }^{1}$, N. N. Kayembe ${ }^{1}$, M. J. Muwonga1 ${ }^{1}$, N. K. Nganga1, N. Ngole', J. P. Elongi2 ${ }^{*}$ \\ ${ }^{1}$ Département de Biologie Médicale, Service de Biologie Cliniques, Cliniques Universitaires de Kinshasa, Kinshasa, Congo \\ ${ }^{2}$ Département de Gynécologie-Obstétrique, Hôpital Générale de Référence de Kinshasa, Kinshasa, Congo \\ Email: dophiebeya@gmail.com, kayembe.donatien@gmail.com, pmuwonga@hotmail.com, mnganga2002@yahoo.fr, \\ mmyngole@gmail.com, *elongi2002@yahoo.fr
}

How to cite this paper: Tshibuela, B.D., Kayembe, N.N., Muwonga, M.J., Nganga, N.K., Ngole, N. and Elongi, J.P. (2017) Relationship between Uricemia and Other Biochemical Markers with the Materno-Fetal Complications during Pre-Eclampsia. Open Journal of Obstetrics and Gynecology, 7, 1255-1261.

https://doi.org/10.4236/ojog.2017.713128

Received: September 7, 2017

Accepted: December 16, 2017

Published: December 19, 2017

Copyright (c) 2017 by authors and Scientific Research Publishing Inc. This work is licensed under the Creative Commons Attribution International License (CC BY 4.0).

http://creativecommons.org/licenses/by/4.0/

\begin{abstract}
Goal: Determining the place of Uricemia associated with other biochemical makers in the prediction of fetal-maternal complications during preeclampsia. Material and method: This is a prospective, cross-sectional study of 75 pre-eclamptic women in three maternities in Kinshasa, Democratic Republic of Congo, during the January to December 2013. The values of the following biochemical markers: uricemia, proteinuria and creatinemia were correlated with maternal and fetal prognosis. Results: This study showed that hyper uricemia associated with massive proteinuria and a high creatinine level correlated with an unfavorable pregnancy outcome and the occurrence of major materno-fetal complications such as eclampsia $(\mathrm{X}$-squared $=24.3598, \mathrm{ddl}=2$, $\mathrm{p}$-value $=0.000005)$ and low birth weight $\left(\mathrm{p}=0.001, \mathrm{R}^{2}=0.08\right)$. Conclusion: In view of these results, it appears necessary to ensure these biochemical markers systematically in the monitoring of pre-eclampsia.
\end{abstract}

\section{Keywords}

Uricemia, Biochemical Markers, Maternal-Fetal Complications, Pre-Eclampsia

\section{Introduction}

Pre-eclampsia is a pregnancy disorder occurring from the $20^{\text {th }}$ week of gestation, associating arterial hypertension (HTA), proteinuria and edema [1] [2] [3] [4]. It is one of the most deadly obstetric conditions, and his severity is related to multiple maternal and fetal complications which may appear during this condition as the HELLP syndrom, eclampsia, hemostasis disorders, renal insufficiency, pulmonary acute edema, retinal detachment, retroplacental hematoma, liver sub 
capsular rupture, hepatocellular insufficiency, acute fetal distress, hypotrophy, prematurity, perinatal asphyxia. Pre eclampsia is therefore one of the major causes of maternal and fetal morbidity and mortality in the world, but especially in the developing countries, where it is responsible for almost $10 \%$ to $25 \%$ of maternal deaths in maternity [5] [6].

Many biological markers have been studied both to reflect the degree of severity of the disease and to predict the occurrence of the some complications. An association between hyperuricemia and materno-fetal complications was noted in these studies. A uric acid level greater than $6 \mathrm{mg} / \mathrm{dl}$ or a rapid increase in this parameter is often associated with the occurrence of maternal and fetal complications such as eclampsia, retro placental hematoma, intrauterine growth retardation and low birth weight [7]-[13].

The proteinuria greater than $1 \mathrm{~g} / 24 \mathrm{~h}$ is the expression of the severe form of hypertension in pregnancy, and has a pejorative value, as it reflects the severity of renal involvement [14] [15]. Similarly, an increase in creatinine levels results in renal insufficiency, the main cause of which is the reduction of glomerular filtration and marked renal plasma flux in severe preeclampsia [16] [17].

The prevalence of pre-eclampsia is estimated at $8.5 \%$ in Kinshasa, Democratic Republic of Congo [4], where the disease is one of the main causes of maternal and perinatal morbidity and mortality. However, very few studies have focused on the value of biological markers in the prediction of complications occurring in this disease. The present study proposes to determine the relationship between uricemia associated with other markers such as creatinemia, proteinuria with materno fetal complications in pre-eclamptics pregnancy in Kinshasa.

\section{Material and Methods}

This cross-sectional and observation study included 75 pre-eclamptics pregnant women, followed at prenatal consultation in three tertiary-level maternities in Kinshasa (DR Congo): Kinshasa University Clinics, The General Reference Hospital of Kinshasa and the Maternity of Kintambo.

\section{Inclusion criteria}

Pregnant women who responded to definition of preeclampsia and gave an informed consent were included in the present study.

Pre-eclampsia has been defined according to the criteria set by the High Blood Pressure Education Program (NHBPEP) by a blood pressure greater than 140/90 $\mathrm{mmHg}$ after $20^{\text {th }}$ week of gestation, associated with a significant proteinuria greater than $300 \mathrm{mg} / 24$ hours [18].

\section{Exclusion criteria}

Pregnant women carriers of disease that can affect the biological markers studied (diabetes, drop, renal failure, chronic hypertension) were excluded from the present study.

Eclampsia was confirmed by the occurrence of convulsions often preceded by headache, visual disturbances and epigastric pains in the absence of cranial 
trauma, anterior epileptic disease and other neurological Convulsive crisis.

Acute renal failure was defined as an increase in serum creatinine $(\geq 1.3$ $\mathrm{mg} / \mathrm{dl}$ ). Low birth weight was defined as a newborn with a weight of less than 2.5 $\mathrm{kg}$ at birth [19]. In utero death results in the absence of fetal cardiac activity. As regards biological parameters values, the normality threshold used in this study was $2.6-5.5 \mathrm{mg} / \mathrm{dl}$ for uricemia [20], $0.5-1.3 \mathrm{mg} / \mathrm{dl}$ for creatinemia, and Levels below $300 \mathrm{mg}$ for 24-hour proteinuria [21].

The chi-square test made to search possible links between various variables (uricemia, proteinuria, maternal complication and mode of delivery). The correlation measure between variables (weight of the new born, uricemia, proteinuria) was calculated using the PEARSON coefficient, with a significance level set at $\mathrm{P}<0.05$.

The present study obtained the approbation of the Ethics Committee of Public Health School of DRC under the /ESP/CE/086/13 registration number.

\section{Results}

During this study period, 75 pre-eclamptics pregnant were included.

The mean age was 31 years (15 - 46 years). The most affected group was $30-$ 34 years as shown in Table 1 . The mean gestational age was 34 weeks Table 1. Mean values of biological parameters in all of these pre-eclamptics were as follows: $5.9 \mathrm{mg} / \mathrm{dl}$ for uricemia, $1.1 \mathrm{mg} / \mathrm{dl}$ for creatinemia, and $1.3 \mathrm{~g} / 24 \mathrm{~h}$ for Proteinuria of 24 hours (Table 2).

Sixty of one hundred pre-eclamptics had delivered by caesarean section. Of these, 55\% had hyper-uricemia. The relationship is established between hyper uricemia and caesarean delivery (Table 3).

We noted in this study that eclampsia and acute renal failure were maternal complications associated with hyperuricemia (Table 4). Pre-eclamptics women with hyperuricemia had a high probability of having low-weight children (Table 5).

A significant positive correlation $\left(\mathrm{R}^{2}=0.14, \mathrm{p}=0.003\right)$ was established be-

Table 1. Main characteristics of the pregnant women enrolled in the study.

\begin{tabular}{cccc}
\hline & minimum & maximum & mean \\
\hline Age women (years) & 15 & 46 & $31 \pm 7$ \\
Gestational age, (weeks) & 21 & 42 & $33 \pm 5$ \\
Parity & 1 & 6 & $2 \pm 1$ \\
\hline
\end{tabular}

Table 2. Mean serum values for uric acid, creatinine and protenuria.

\begin{tabular}{cccc}
\hline & minimum & maximum & mean \\
\hline Uric acid $(\mathrm{mg} / \mathrm{dl})$ & 2.5 & 14 & $5.9 \pm 2.6$ \\
creatinine $(\mathrm{mg} / \mathrm{dl})$ & 0.5 & 6.7 & $1.14 \pm 1.1$ \\
protenura/24h & 0.50 & 10 & $1.28 \pm 1.2$ \\
\hline
\end{tabular}


Table 3. Association between mode of delivery and uric acid levels $(n=75)$.

\begin{tabular}{ccc}
\hline \multirow{2}{*}{ Uricémie $(\mathrm{mg} / \mathrm{dL})$} & \multicolumn{2}{c}{ Mode of delivery } \\
\cline { 2 - 3 } & Normal (\%) & Cesarean section \\
\hline 55.5 & 32 & 26,7 \\
$>5.5$ & 8 & 32.9 \\
Total & 40 & 59.6 \\
\hline
\end{tabular}

X-squared 6.880, $\mathrm{ddl}=1, \mathrm{P}$-Value $=0.008$

Table 4. Association between maternal complicatons and uric acid levels $(n=75)$.

\begin{tabular}{ccccc}
\hline \multirow{2}{*}{ uric acid levels } & \multicolumn{3}{c}{ maternal complicatons } & \multirow{2}{*}{ Total } \\
\cline { 2 - 4 } & Acute renal failure & Eclampsia & none complications & \\
\hline$\leq 5.5$ & 1 & 1 & 38 & 40 \\
$>5.5$ & 5 & 12 & 12 & 29 \\
Total & 6 & 13 & 50 & 69 \\
\hline
\end{tabular}

$\mathrm{X}$-squared $=24.3598, \mathrm{ddl}=2, \mathrm{p}$-value $=0.000005$

Table 5. Correlation between weight of the new born and uric acid levels $(n=75)$.

\begin{tabular}{ccc}
\hline & \multicolumn{3}{c}{ Uric acid levels $(\mathrm{mg} / \mathrm{dL})$} \\
\cline { 2 - 3 } weight of the new born $(\mathrm{kg})$ & $\mathbf{5}$ & $>\mathbf{5 . 5}$ \\
\cline { 2 - 4 } & \multicolumn{1}{c}{$\%$} & $\%$ \\
\hline$\leq 2.5$ & 13.2 & 26.3 \\
$>2.5$ & 44.7 & 15.8 \\
Total & $\mathbf{5 7 . 9}$ & $\mathbf{4 2 . 1}$ \\
\hline
\end{tabular}

$\mathrm{p}=0.001,\left(\mathrm{R}^{2}=0.08\right)$

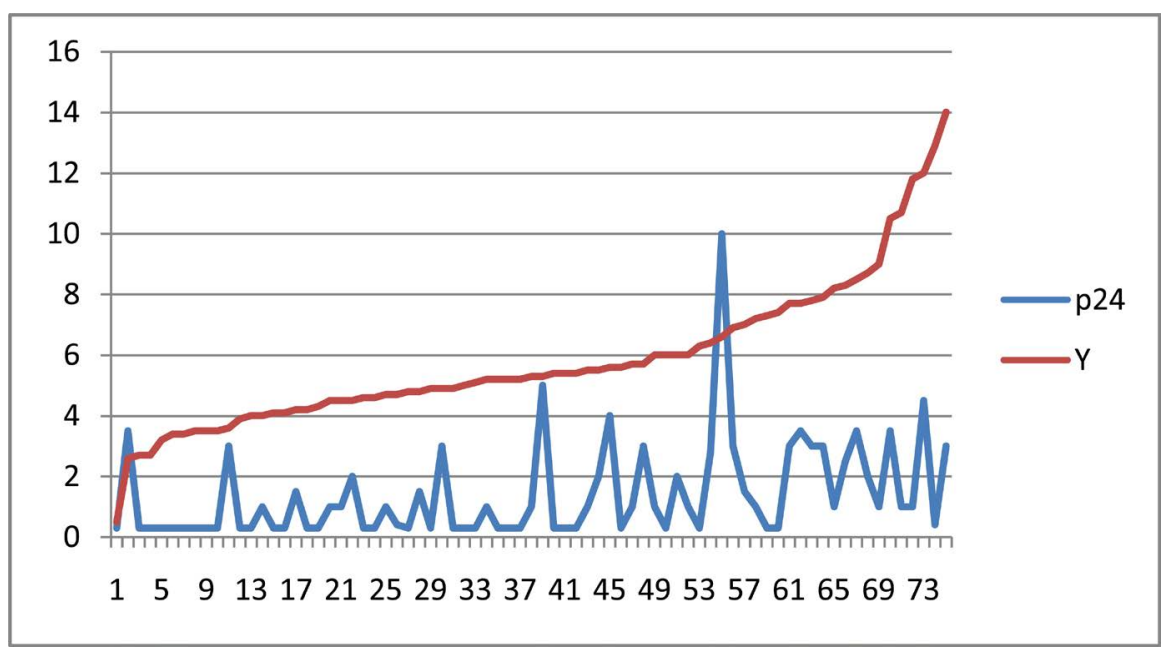

$\mathrm{P} 24$ = protenuria de 24 heures; $\mathrm{Y}=$ uric acid levels; $\mathrm{R}^{2}=0.13 \mathrm{P}$-Value $=0.003$

Figure 1. Correlation between proteinuria and uric acid levels $(n=75)$.

tween uricemia and 24-hour proteinuria. Hyperuricemia corresponds to the high level of proteinuria (Figure 1). There is an association between uricemia and creatinin at the significance level $(p=0.01)$, these variables are linked to an 
Table 6. Correlation between creatinemia and uric acid levels $(n=75)$.

\begin{tabular}{cccc}
\hline & \multicolumn{3}{c}{ Creatinemia } \\
\cline { 2 - 4 } Uric acid levels & $\leq 1.3$ & $>1.3$ & Total \\
\hline$\leq 5.5$ & 40 & 4 & 44 \\
$>5.5$ & 24 & 8 & 31 \\
Total & 64 & 12 & 75 \\
\hline
\end{tabular}

$\mathrm{R}^{2}=0.13 ; \mathrm{P}$-Value $=0.001$

estimated correlation level of $0.365\left(R^{2}=0.13\right)($ Table 6).

\section{Discussion}

In the study by Corine $\mathrm{M}$ et al. [22], it has been demonstrated that hyper uricemia in the context of pre-eclampsia is associated with a high rate of eclampsia. Thagaratinam et al. [23] estimated that high serum uric acid levels were associated with an almost double risk of severe complications such as eclampsia with a high caesarean section. Valentin et al. [24] describe uricemia as the most discriminating parameter at all stages of the disease from the twentieth week of gestation The present study showed that hyper uricemia was significantly correlated with the emergence of eclampsia and a high incidence of caesarean section; corroborating the results of Thagaratinam, Valentin, Corine M. Koopmans. The rate of caesarean section associated with hyperuricemia found in our study (33\%) is similar to that of Gowri et al. [22].

We found in this study, among the 22 pre-eclamptic pregnant women who gave birth to low-birth-weight children, 68\% had hyper uricemia. Nida [23] notes in his study that fetal hypotrophy is often associated with hyperuricemia, making this biological parameter a very reliable index of fetal prognosis. During pre-eclampsia, there are pathognomonic renal lesions known as "glomerular endotheliosis", which are the basis of decreased plasma renal flow and glomerular filtration, proteinuria noted during the disease, Creatinemia and uricemia. Its importance is correlated with the severity of renal involvement. Like RAGHEB [25] and CHAOUI [24], our study found a link between the occurrence of acute renal failure in preeclamptic pregnant women, 24-hour severe proteinuria, elevated serum creatinine, and hyper uricemia.

\section{Conclusion}

Hyperuricemia in preeclampsia is a risk factor for eclampsia, low birth weight, and is associated with a high rate of caesarean sections. Associated with a massive proteinuria and a high creatinine, hyper uricemia translates the important renal impairment in the evolution of the disease.

\section{References}

[1] Expert Conference (2000) Epidemiology of Preeclampsia. In: French Society of Anaesthesia and Resuscitation (SFAR). Resuscitation of Severe Forms of 
Preeclampsia, Elsevier, Paris, 25-34.

[2] Pourrrat, O. (2004) Pre-eclampsia et eclampsia: therapeutic Progress. Department of medecine Réanimation and internal, CHU de Poitier, 178-186.

[3] Elongi, M.J.P., Tandu, U., Spitz, B. and Verdonck, F. (2011) Influence of the Seasonal Variation on the Prevalence of Pre-Eclampsia in Kinshasa. Gynécologie Obstétrique \& Fertilité, 39, 132-135. https://doi.org/10.1016/j.gyobfe.2010.12.010

[4] Hariolynirina, M.O.J., et al. (2009) Epidémiology Profile of Pre-Eclampsia and Eclampsia Admitted in Maternity of Befelatanana. Revue d'Anesthésie-Réanimation et de Médecine d' Urgence, 1, 22-24.

[5] Karumanchi, S.A. and Lam. C. (2004) Mechanism Involved in Pré-Éclampsia: Recent Progress. Flammarion Médecine-Sciences, Néphrologic Actuality, 167-175.

[6] Hind, M. (2007) grip charge of pré-éclampsia and éclampsia in chirurgicale reanimation (a 97 cas words). University of sidi Mohammed ben Abdellah Faculty of Medecine and Pharmacy, Thesis $\mathrm{N}^{\circ} 024 / 07$.

[7] Powers, R.W., Bodnar, L.M. and Ness, R.B., et al. (2006) Uric Acid Concentration in Early Pregnancy among Preeclamptic Women with Gestational Hyperuricemia at Delivery. American Journal of Obstetrics and Gynecology, 194, 160. https://doi.org/10.1016/j.ajog.2005.06.066

[8] Wolak, T., Sergienko, R., Wiznitzer, A., Paran, E. and Sheiner, E. (2012) High Uric Acid Level during the First 20 Weeks of Pregnancy Is Associated with Higher Risk for Gestational Diabetes Mellitus and Mild Preeclampsia. Hypertens Pregnancy, 31, 307-315. https://doi.org/10.3109/10641955.2010.507848

[9] Williams, K.P. and Galerneau, F. (2002) The Role of Serum Uric Acid as a Prognostic Indicator of the Severity of Maternal and Fetal Complicationsin Hypertensive Pregnancies. Journal of Obstetrics and Gynaecology Canada, 24, 687-639. https://doi.org/10.1016/S1701-2163(16)30193-1

[10] Bellomo, G., Venanzi, S., Saronio, P., Verdura, C. and Narducci, P.L. (2011) Prognostic Significance of Serum Uric Acid in Women with Gestational Hypertension. Hypertension, 58, 704-708. https://doi.org/10.1161/HYPERTENSIONAHA.111.177212

[11] Vázquez-Rodríguez, J.G. and Rico-Trejo, E.I. (2011) Role of Uric Acid in Preeclampsia-Eclampsia. Ginecología y obstetricia de México, 79, 292-297.

[12] Nwagha, U.I., Ejezie, F.E. and Iyare, E.E. (2009) Evaluation of Serum Uric Acid Levels in Normal Pregnant Nigerian Women. Nigerian Journal of Clinical Practice, $12,83-86$.

[13] Johnson, R.J., Kanbay, M., Kang, D.-H., Sa'nchez-Lozada, L.G., Room, D.F. and Aurora (2011) Uric Acid A Clinically Useful Marker to Distinguish Preeclampsia From Gestational Hypertension. Hypertension, 58, 548-549. https://doi.org/10.1161/HYPERTENSIONAHA.111.178921

[14] Salako, B.L., Odukogbe, A.T., Olayemi, O., Adedapo, K.S., Aimakhu, C.O., Alu, F.E. and Ola, B. (2003) Serum Albumin, Creatinine, Uric Acid and Hypertensive Disorders of Pregnancy. East African Medical Journal, 80, 424-428.

[15] Roberts, J.M., Bodnar, L.M. and Lain, K.Y., et al. (2005) Uric Acid Is as Important as Proteinuria in Identifying Fetal Risk in Women with Gestational Hypertension. Hypertension, 46, 1263-1265. https://doi.org/10.1161/01.HYP.0000188703.27002.14

[16] Olowu-salako, A. (2001) Grip Charge Severes Renal Vesicle Syndrome of the Pregnancy in Maternity of Lagune de Cotonou. Th. Méd., Cotonou, No. 960.

[17] Liedhalm, H., Montan, S. and Aberg, A. (1984) Risk Grouping of 113 Patients with 
Hypertensive Disorders during Pregnancy, with Respect to Serum Urate, Protienura and Time of Onset of Hypertension. Acta Obstetricia et Gynecologica Scandinavica, $1,1370-1373$.

[18] (2001) Report of the National High Blood Pressure Education Program Working Group on High Blood Pressure in Pregnancy. American Journal of Obstetrics \& Gynecology, 185, 522-523.

[19] Gowri, V. and Zakuani, A.L. (2010) Prevalence of Cesarean Delivery in Pré-éclamptic Patients with Elevated Uric Acid. Hypertension in Pregnancy, 29, 231-235.

[20] Nida, C. (1997) Contribution to the Study of Hypertension in the Course of Pregnancy au CNHU de Cotonou. Th. Méd. Cotonou, No. 732.

[21] Chaoui, A., Tyane, M. and Belouali, R. (2002) Grip Charge of Pre-Eclampsia and Eclampsia. 2nd Conference Consensus National MAROC, Marrakech, 19-21.

[22] Corine, M.K., van Pampusa, M.G., Groenb, H. and Jan G.A. (2009) Accuracy of Serum Uric Acid as a Predictive Test for Maternal Complications in Pre Eclampsia: Bivariate Meta-Analysis and Decision Analysis. The European Journal of Obstetrics \& Gynecology and Reproductive Biology, 146, 8-14.

[23] Thangaratinam, S., et al. (2006) Accuracy of Serum Uric Acid in Predicting Complication of Pré-éclampsie: A Systematic Review. BJOG, 113, 36-39. https://doi.org/10.1111/j.1471-0528.2006.00908.x

[24] Valentin, B., Laffargue, F., Daures, J.P. and Dujols, P. (1985) Evaluation des moyens cliniques et biologique d'appréciation du pronostic fœetal dans la toxémie gravidique. Journal de Gynécologie Obstétrique et Biologie de la Reproduction, 14, 499-505.

[25] Ragheb, T. (2002) Piont of View of the Obstetrician Casablanca. Thesis s Med, No. 26. 